\title{
Author Correction: Evidence of supershear during the 2018 magnitude 7.5 Palu earthquake from space geodesy
}

Anne Socquet (D), James Hollingsworth (D), Erwan Pathier (iD) and Michel Bouchon

Correction to: Nature Geoscience https://doi.org/10.1038/s41561-018-0296-0, published online 4 February 2019.

There were some typographical errors in the version of this Article originally published; all the following have now been corrected. In the final sentence of the section 'Intermediate displacement field as seen from InSAR', "pleading for local transpression" should be "leading to local transpression". In the first sentence of Fig. 3 caption, "plotted along the strike by latitude" should be "plotted along strike by latitude", and in the second sentence, "swatch" should be "swath". In the final sentence of the section "Rupture characteristics and evidence for supershear', "shear horizontal waves" should be "horizontal shear waves". In the first paragraph of 'Slip distribution', "normal slips" should be "normal slip". In the second sentence of the section 'Seismic cycle balance, "corresponds to a moment deficit" should be "which corresponds to a moment deficit"; and in the penultimate sentence "two years later a Mw 6.6 earthquake on the Palu fault ${ }^{10 "}$ should be "a Mw 6.6 earthquake on the Palu fault two years later ${ }^{10 "}$. Finally, in the third sentence of the 'Conclusions' section, "time function" should be "source time function".

Published online: 5 March 2019

https://doi.org/10.1038/s41561-019-0337-3

\section{Author Correction: Fully oxygenated water columns over continental shelves before the Great Oxidation Event}

Chadlin M. Ostrander (D), Sune G. Nielsen D, Jeremy D. Owens, Brian Kendall, Gwyneth W. Gordon, Stephen J. Romaniello and Ariel D. Anbar

Correction to: Nature Geoscience https://doi.org/10.1038/s41561-019-0309-7, published online 25 February 2019.

In the version of this Article originally published, Fig. 1 was incorrectly mentioned in the caption for Fig. 3; the citation should have been to Fig. 2. This has now been corrected.

Published online: 6 March 2019

https://doi.org/10.1038/s41561-019-0339-1 